\title{
Preparation of the Silicone-Modified Antimicrobial Polyethylene Endotracheal Tube (PE ETT)
}

\author{
Xuhong $\mathbf{J}^{1,2 *}$, Bin $\mathbf{L V}^{1,2}$, Xinmin $\mathbf{W}^{3}$ and Qianhong $\mathbf{S}^{3}$ \\ ${ }^{1}$ The First Clinical Medical College of Zhejiang Chinese Medical University, Hangzhou, China \\ ${ }^{2}$ Emergency Department, The First Affiliated Hospital of Zhejiang Chinese Medical university, Hangzhou, China \\ ${ }^{3}$ Zhejiang-California International NanoSystems Institute, Zhejiang University, Hangzhou, China
}

\begin{abstract}
Polyethylene endotracheal tube (PE ETT) antimicrobial coating has been proved to be a more effective method to prevent endoluminal biofilm formation. A transparent silicone-modified antimicrobial PE ETT was obtained by coating $\mathrm{SiO}_{2} / \mathrm{KH} 570 / \mathrm{MTES} / \mathrm{Ag}-\mathrm{SiO}_{2}$ solution prepared by chemical mixing $\mathrm{Ag}-\mathrm{SiO}_{2}$ and $\mathrm{SiO}_{2} / \mathrm{KH} 570 / \mathrm{MTES}$ solution by means of dip-coating method, followed by drying. All the films were characterized by various techniques including Pencil Hardness Tester, IR, SEM, UV-vis, and ICP-MS. The results indicated that the TEOS/KH570/MTES/Ag-SiO (15:6:1:0.6 1.0) films, which exhibit the simple solution-processable film formation on PE ETT, show homogeneous morphology, and have the high transmittance of above $87 \%$, high hardness of $5 \mathrm{H}$, strong adhesion. Furthermore, the silicone-modified antimicrobial PE ETTs show excellent antimicrobial property with the sterilization rate up to $93.5 \%$, it demonstrates that the antimicrobial films have excellent biocompatibility and potent antimicrobial activity against protein adhesion. Pyrogen test, hemolysis test and oral mucous irritation test results are fit for biosecurity use requirement for biological materials. So, silicone-modified antimicrobial PE ETT is hoped to be used in the field of medical materials and can be used as an efficient and economical method to extend the service life of the PE ETT.
\end{abstract}

Keywords: Endotracheal tube; Antimicrobial film; Silicone; $\mathrm{Ag}-\mathrm{SiO}_{2}$

\section{Introduction}

Ventilator-associated pneumonia (VAP) is a common complication for mechanical ventilation patients in ICU and trachea cannula, repeated cannula and mechanical ventilation way and mechanical ventilation time are one VAP vulnerable factor [1]. Endotracheal tube (ETT) is artificial biomaterial and it does not have antibacterial property. Once inserted into human body, it becomes the potential source of infection because pathogenic bacteria is absorbed on its surface for growing and breeding to form bacterial biofilm which can adhere dissociated bacteria and avoid bacteria from killing and phagocytosing under the effect of antibiotics and body's immune system [2]. In order to prevent infection after biomaterial placement, the antibacterial coatings are painted on its surface, such as nanoZnO [3], $\mathrm{TiO}_{2}$ photocatalytic materials [4], Ag-loaded coating [5], etc to inhibit bacteria from adhering on the surface of cannula to form bacterial biofilm.

Among that, there is more research for Ag-loaded coatings in antibacterial materials that $\mathrm{Ag}+$ ion can destroy cell division and mutual respiratory function of bacteria and virus, having stronger bactericidal ability and inhibiting pathogen activity [6,7]. However, there is less research for Ag-loaded antibacterial coating in biomedical materials. The majority research is concentrated on modified or composited antibacterial materials and it is rearly verified for moldability and biocompatibility of antibacterial coatings. Furthermore, $\mathrm{Ag}^{+}$ion is sedimented on the surface of biomaterial or in the meso pore through ion exchange and physical absorption [8]. The poor binding force with base material leads to antibacterial coating shedding, influencing on its antibacterial property and safety. So people prepare antibacterial coatings by recombinating polymer and $\mathrm{Ag}^{+}$ion to enhance binding force between antibacterial coating and base material and improve compactibility, such as polyvinylpyrrolidone [9], polyurethane [10], chitosan [11], etc. However, there is less research for silicone materials. Silicone materials contain many kinds of active group and present excellent cohesiveness and film-processing property [12]. The hydrophobic groups of $\mathrm{Si}-\mathrm{CH}_{3}$ and $-\mathrm{CH}_{3}$ could reduce coating surface energy and improve chemical inertness. Its polymer is compatible with tissue and blood of human body and has certain anticoagulation in effect so it is widely applied in biomaterials [13].

In this study, silicon compound of $\mathrm{SiO}_{2} / \mathrm{KH} 570$ and $\mathrm{SiO}_{2} / \mathrm{KH} 570 /$ MTES prepared through the sol-gel process with TEOS as inorganic silicon source, KH570 and MTES as the organicsilicon source, were used to prepare series silicone-modified antimicrobial films on conventional PE ETT by mixing silver antibacterial agent. Effects of different alkoxysilanes of KH570 and MTES content on the properties of silicon compound solutions and their films were investigated. We also study the influence of different $\mathrm{Ag}-\mathrm{SiO}_{2}$ content on the stability of the silicone-modified antimicrobial solution and the sterilizing rate of their films. A transparent silicone-modified antimicrobial PE ETT and their properties were introduced in this paper. Its biosecurity is verified in pyrogen test, hemolysis test and oral mucous irritation test. Such silicone-modified antibacterial coatings are hoped to be used in surface coating field of medical materials or medical apparatus and instruments to improve infection situation in the hospital.

\section{Materials and Methods}

\section{Regents and materials}

Tetraethyl orthosilicate (TEOS), $\quad \gamma$-Methacryloxy propyl

*Corresponding author: Jiang Xuhong, Shangcheng Huansha road 54, Hangzhou city, Zhejiang, China, Tel: +8615988890828; E-mail: anhong2225@163.com

Received June 25, 2014; Accepted September 23, 2014; Published September 25,2014

Citation: Xuhong J, Bin LV, Xinmin W, Qianhong S (2014) Preparation of the Silicone-Modified Antimicrobial Polyethylene Endotracheal Tube (PE ETT). J Med Microb Diagn 3: 163. doi:10.4172/2161-0703.1000163

Copyright: ( 2014 Xuhong J, et al. This is an open-access article distributed under the terms of the Creative Commons Attribution License, which permits unrestricted use, distribution, and reproduction in any medium, provided the original author and source are credited. 
trimethoxylsilane (KH570), methacryltriethoxysilane (MTES), silver antibacterial agent $\left(\mathrm{Ag}-\mathrm{SiO}_{2}\right)$, ethanol, distilled water, acetic acid and potassium oxalate were analytically grade. $0.9 \%$ sodium chloride injection, Zhejiang Shapuaisi Pharmaceutical Co. Ltd. Normal PE tracheal cannula (blank ETT), Covidien.

\section{Preparation of antimicrobial coating}

The silicone-modified antimicrobial solution were synthesized by sol-gel method and mechanical mixing as described in Figure 1. In the preparation of silicon compound solutions of $\mathrm{SiO}_{2} / \mathrm{KH} 570$ and $\mathrm{SiO}_{2} /$ KH570/MTES, TEOS were first diluted in ethanol with subsequent hydrolysis in water by catalyst under vigorous stirring at the room temperature, then mixed with different amounts of KH570 or the mixture of KH570 and MTES at different ratio were added under stirring until completely hydrolyzing and crossing linked with silica solution. The films of $\mathrm{SiO}_{2} / \mathrm{KH} 570$ and $\mathrm{SiO}_{2} / \mathrm{KH} 570 /$ MTES were obtained by dip-coating on PE ETT. The silicone-modified antimicrobial solution of TEOS/KH570/MTES/Ag-SiO 2 was prepared by shear mixing Ag$\mathrm{SiO}_{2}$ with the silicon compound solutions of $\mathrm{SiO}_{2} / \mathrm{KH} 570 /$ MTES.

Figure 2 shows the flow diagram of the preparation of the siliconemodified antimicrobial PE ETT. The PE ETT were treated by corona discharging, then dipped into the solution of TEOS/KH570/MTES/ $\mathrm{Ag}-\mathrm{SiO}_{2}$, finally baked at $80 \sim 100^{\circ} \mathrm{C}$ for $1 \mathrm{~h}$ to obtain the antimicrobial

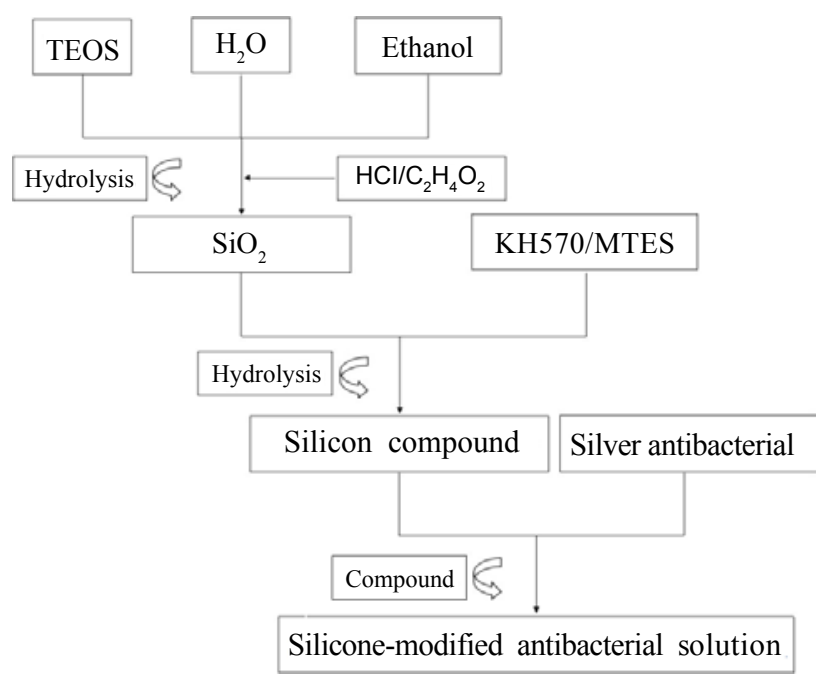

Figure 1: Flow diagram of the synthesis of silicone-modified antimicrobial solutions.

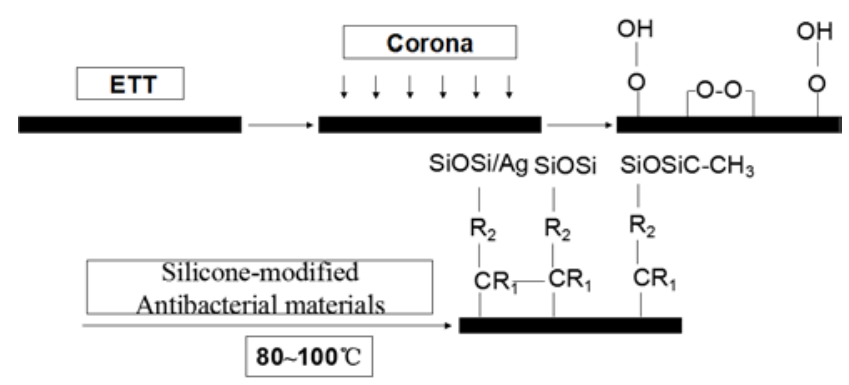

Figure 2: Flow diagram of the preparation of silicone-modified antimicrobial PE ETT.
PE ETT with high transmittance and silicone-modified antimicrobial PE ETT

\section{Characterization of the materials}

The hardness and adhesion of all the films were measured by pencil hardness tester and Squaring-off, respectively. Infrared spectrums (IR) of two gels of TEOS/KH570/MTES and TEOS/KH570/MTES/ $\mathrm{Ag}-\mathrm{SiO}_{2}$ were performed on IR spectrometer. The micrograph and transmittance of the resulting films were measured by scanning electronic microscope (SEM) and a UV spectrometer. The antimicrobial property was evaluated by the method described as GBT 21866-2008 Test method and effect for antibacterial capability of paints film, and the precipitation of $\mathrm{Ag}^{+}$ion was measured by inductively coupled plasma mass spectrometry (ICP-MS). The biosecurity used in the field of medical materials was evaluated by Pyrogen test, hemolysis test and oral mucous irritation test.

\section{Results}

\section{The hardness and adhesion of the films and the stability of the solutions}

Organosilicone with various active groups like $\mathrm{Si}-\mathrm{OH}, \mathrm{R} 1-\mathrm{COO}-\mathrm{R}$, $\mathrm{Si}-\mathrm{O}-\mathrm{Si}$, etc, is especially preferred to enhance the adhesion of hybrid films on many substrates. KH570 with long chain is an excellent organic modified silicone, which can improve the flexibility of films, and MTES with two stiff groups of $\mathrm{CH}_{3}$ gives the film an improved hardness and is considered to have influence on reducing the interface energy to prevent protein adhesion. So we investigated the ratio of TEOS, KH570 and MTES in order to make better performance films and solutions. The hardness and adhesion of the obtained films including TEOS/KH570, TEOS/KH570/MTES and TEOS/KH570/ $\mathrm{MTES} / \mathrm{Ag}-\mathrm{SiO}_{2}$, and the storage stability of their solutions are showed in Table 1. The result silicon solution of TEOS/KH570 was flocculated and their film has worse adhesion when the ratio of TEOS and KH570 is 18:3. With increasing the KH570 content, the TEOS/KH570 films exhibit strong adhesion, and their solutions have good storage stability at room temperature for $72 \mathrm{~h}$, but the hardness reduce from $7 \mathrm{H}$ to $1 \mathrm{H}$. The films with TEOS:KH570 ratio of 15:6 and 13:8 exhibited desirable hardness of $3 \mathrm{H}$ and $5 \mathrm{H}$ and excellent adhesion, were investigated further to prepare a higher-quality basic film for the antimicrobial film on PE ETT. MTES used to prepared TEOS/KH570/MTES films can exactly enhance the hardness of the films but sacrifice the adhesion property. So it is especially desirable to keep TEOS/KH570/MTES at the ratios of $15: 6: 1$ and 13:8:1 to prepared the silicone-modified antimicrobial solution by mixing different content of $\mathrm{Ag}-\mathrm{SiO}_{2}$. The TEOS:KH570:MTES:Ag-SiO ${ }_{2}$ films with lower $\mathrm{Ag}-S i O_{2}$ content performed high hardness and strong adhesion, and their solutions are stable when the ratio of TEOS:KH570:MTES:Ag-SiO ${ }_{2}$ is 15:6:1:0.3, 15:6:1:0.8, 13:8:1:0.3 and 13:8:1:0.8, the solution become unstable and sediment can be observed with too much more $\mathrm{Ag}-\mathrm{SiO}_{2}$ because of the agglomerating of nanoparticles.

\section{Constituent phase of the films}

The IR spectrum of resulting films of TEOS/KH570/MTES (15:6:1) and TEOS/KH570/MTES/Ag-SiO 2 (15:6:1:0.8) are shown in Figure 3(a) and 3(b), respectively. Obviously, the IR spectrums are similar and the analyses are gave in Table 2 . The broad peak at $3440 \mathrm{~cm}^{-1}$ was assigned to $\mathrm{O}-\mathrm{H}$ bonds, the strength of that peak in (b) is stronger, because of much more $\mathrm{Si}-\mathrm{OH}$ groups on the surface of $\mathrm{Ag}-\mathrm{SiO}_{2}$. The presence of a strong peak between $1000 \mathrm{~cm}^{-1}$ and $1110 \mathrm{~cm}^{-1}$ was attributed to 


\begin{tabular}{|c|c|c|c|c|c|}
\hline Samples & $\begin{array}{l}\text { Ratio } \\
(\mathrm{ml} / \mathrm{ml})\end{array}$ & $\underset{(\mathrm{ml} \%)}{\mathrm{Ag}}$ & $\begin{array}{l}\text { Hardness } \\
\text { (H) }\end{array}$ & Adhesion & Stability \\
\hline \multirow[t]{5}{*}{ TEOS/KH570 } & $18: 3$ & 0 & $7 \mathrm{H}$ & 1 & Gel \\
\hline & $15: 6$ & 0 & $5 \mathrm{H}$ & 0 & $\sqrt{ }$ \\
\hline & $13: 8$ & 0 & $3 \mathrm{H}$ & 0 & $\sqrt{ }$ \\
\hline & $11: 10$ & 0 & $2 \mathrm{H}$ & 0 & $\sqrt{ }$ \\
\hline & $8: 13$ & 0 & $1 \mathrm{H}$ & 0 & $\sqrt{ }$ \\
\hline \multirow[t]{6}{*}{ TEOS/KH570/MTES } & $15: 6: 1$ & 0 & $5 \mathrm{H}$ & 0 & $\sqrt{ }$ \\
\hline & $15: 6: 3$ & 0 & $6 \mathrm{H}$ & 4 & $\sqrt{ }$ \\
\hline & $15: 6: 5$ & 0 & $6 \mathrm{H}$ & 5 & $\sqrt{ }$ \\
\hline & $13: 8: 1$ & 0 & $3 \mathrm{H}$ & 0 & $\sqrt{ }$ \\
\hline & $13: 8: 3$ & 0 & $4 \mathrm{H}$ & 3 & $\sqrt{ }$ \\
\hline & 13:8:5 & 0 & $4 \mathrm{H}$ & 5 & $\sqrt{ }$ \\
\hline \multirow{6}{*}{$\begin{array}{l}\text { TEOS/KH570/MTES/ } \\
{\mathrm{Ag}-\mathrm{SiO}_{2}}\end{array}$} & $15: 6: 1: 0.3$ & 1.3 & $5 \mathrm{H}$ & 0 & $\sqrt{ }$ \\
\hline & $15: 6: 1: 0.8$ & 3.5 & $5 \mathrm{H}$ & 0 & $\sqrt{ }$ \\
\hline & $15: 6: 1: 1.5$ & 6.4 & $5 \mathrm{H}$ & 0 & Deposit \\
\hline & $13: 8: 1: 0.3$ & 1.3 & $3 \mathrm{H}$ & 0 & $\sqrt{ }$ \\
\hline & $13: 8: 1: 0.8$ & 3.5 & $3 \mathrm{H}$ & 0 & $\sqrt{ }$ \\
\hline & $13: 8: 1: 1.5$ & 6.4 & $3 \mathrm{H}$ & 0 & Deposit \\
\hline \multicolumn{6}{|c|}{$\begin{array}{l}\text { Note: (1) Films' thickness is between } 200 \text { and } 400 \mathrm{~nm} \text {; } \\
\text { (2) Hardness test: ISO15184-2012; } \\
\text { (3) Adhesion test: ISO2409-2007; } \\
\text { (4) Storage stability test: samples to stand at room temperature for } 72 \mathrm{~h} \text { to observe whether flocculation or sediment. }\end{array}$} \\
\hline
\end{tabular}

Table 1: The hardness and adhesion of the films and the storage stability of the solutions.

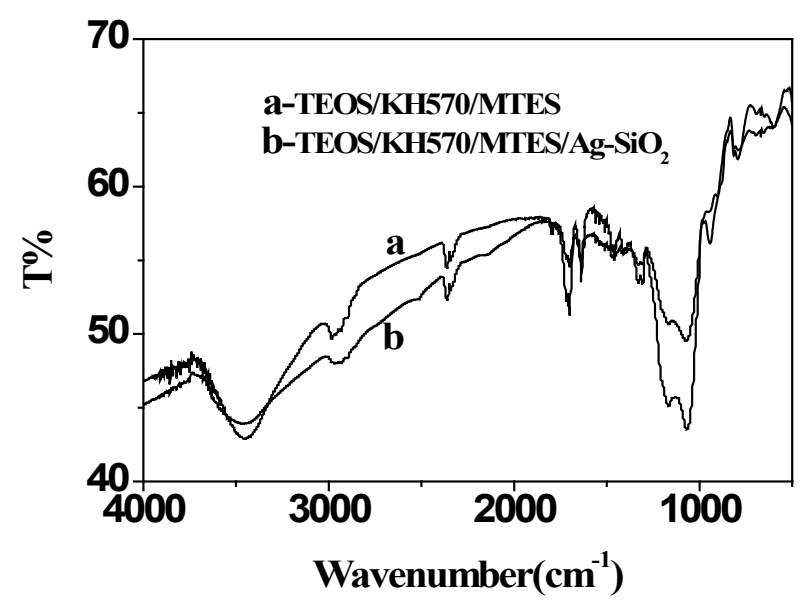

Figure 3: IR of (a) the TEOS/KH570/MTES (15:6:1); (b) the TEOS/KH570/ MTES/Ag-SiO 2 (15:6:1:0.8)

the stretching vibration of $\mathrm{Si}-\mathrm{OH}$ or $\mathrm{Si}-\mathrm{O}-\mathrm{Si}$ group, which indicated that TEOS, KH570 and MTES had been reacted sufficiently. The C-H stretching peak at $2850 \sim 3000 \mathrm{~cm}^{-1}$ in the spectrum can be an indication of $\mathrm{Si}-\mathrm{OC}_{2} \mathrm{H}_{5}$ and- $\mathrm{CH}_{3}$ groups mainly from $\mathrm{KH} 570$ and MTES. The IR spectrums reflect that TEOS/KH570/MTES and $\mathrm{Ag}-\mathrm{SiO}_{2}$ have well compatibility, which is consistent with the SEM analysis.

\section{Surface morphology of the films}

The surface of coatings is uniform and flat in Figure 4(a) without granule and phase separation. Meanwhile, Ag antibacterial agent content is little in Figure 4(b) coatings imbedded by silicone network polymer, it is not found $\mathrm{Ag}$ antibacterial agent particles and the surface is flat. It shows SEM micrographs of the films of TEOS/KH570/MTES and TEOS/KH570/MTES/Ag-SiO, which were prepared by dipcoating the solution on ETT and baked at $80^{\circ} \mathrm{C}$ for $1 \mathrm{~h}$. The films is smooth and crack-free, the SEM results show that the films are uniform

\begin{tabular}{|c|c|c|}
\hline Samples & $\begin{array}{l}\text { Wavenumber, } \\
\mathbf{c m}^{-1}\end{array}$ & groups \\
\hline \multirow[t]{5}{*}{ Fig. (a) } & 3446 & $\mathrm{Si}-\mathrm{OH}$ \\
\hline & $2850 \sim 3000$ & $\mathrm{Si}-\mathrm{OC}_{2} \mathrm{H}_{5},-\mathrm{CH}_{3}, \mathrm{C}-\mathrm{H}$ \\
\hline & 1740 & $-\mathrm{C}=\mathrm{O}$ ）-O-R \\
\hline & 1400 & $-\mathrm{CH}_{3}$ \\
\hline & $1110 \sim 1000$ & Si-O-Si \\
\hline \multirow[t]{5}{*}{ Fig. (b) } & 3446 & $\mathrm{Si}-\mathrm{OH}$ \\
\hline & $2850 \sim 3000$ & $\mathrm{Si}-\mathrm{OC}_{2} \mathrm{H}_{5},-\mathrm{CH}_{3}, \mathrm{C}-\mathrm{H}$ \\
\hline & 1740 & $-\mathrm{C}=\mathrm{O})-\mathrm{O}-\mathrm{R}$ \\
\hline & 1400 & $-\mathrm{CH}_{3}$ \\
\hline & $1110 \sim 1000$ & $\mathrm{Si}-\mathrm{O}-\mathrm{Si}$ \\
\hline
\end{tabular}

Table 2: Analyses of the infrared spectrum.

and amorphous, there is no significant inorganic domain size shown in the two series of films. It indicates that there is a crosslinking of silica sol with alkoxysilanes, and $\mathrm{Ag}-\mathrm{SiO}_{2}$ has been homogeneously dispersed in TEOS/KH570/MTES/Ag-SiO ${ }_{2}$ film.

\section{Transmittance of the films}

Figure 5 shows the optical transmittance spectra of ETT (a), ETT coated with TEOS/KH570/MTES film (b) and ETT with TEOS/KH570/ MTES/Ag-SiO film (c). The PE ETTs before or after coating with the solution maintained the high transmittance, which are $87.55 \%, 87.45 \%$ and $87.39 \%$, respectively. There is no absorption can be observed in the figure, which indicates that nanoparticles have been homogeneously dispersed in the films, all the films on ETT's surfaces are homogeneous, and the condensation reaction between the hydroxyl groups of the hydrolysates of the alkoxysilanes and the hydroxyl groups on the surface of the colloidal silica from $\mathrm{SiO}_{2}$ sol and $\mathrm{Ag}-\mathrm{SiO}_{2}$ have occurred. It means that antibacterial coating can increase transmittance which keeps the original appearance of ETT and improves its view definition in the application process, convenient for clinical observation.

\section{Antimicrobial property}

The antimicrobial property of TEOS/KH570/MTES/Ag-SiO ${ }_{2}$ films 

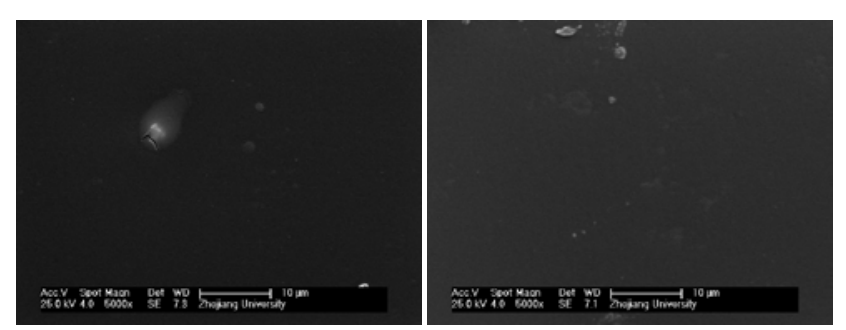

Figure 4: SEM of the films of (a) TEOS/KH570/MTES (15:6:1); (b) TEOS/ KH570/MTES/Ag-SiO ${ }_{2}$ (15:6:1:0.8).

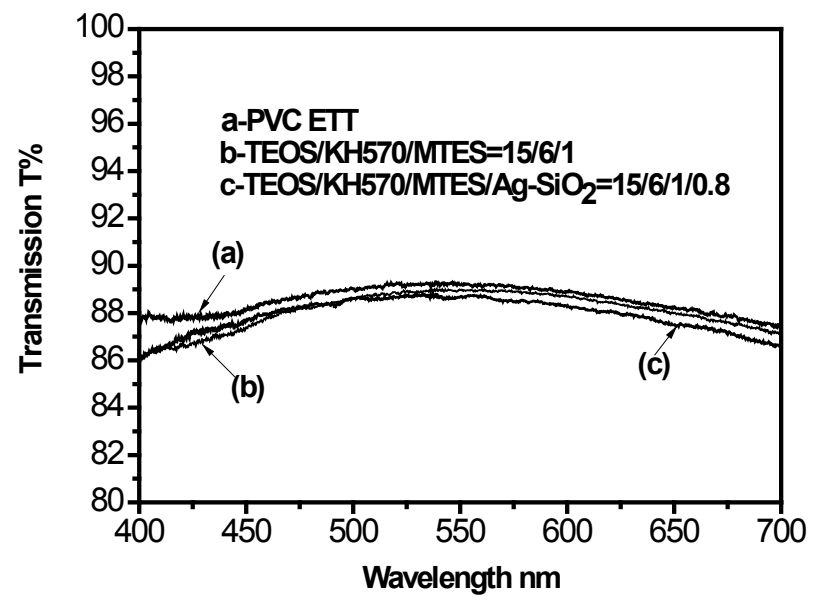

Figure 5: The transmittance of PVE ETT coated with (a) blank; (b) TEOS/ KH570/MTES; (c) TEOS/KH570/MTES/Ag-SiO 2

\begin{tabular}{|c|c|c|c|}
\hline Samples & Ratio (ml:ml) & $\operatorname{Ag}(\mathrm{ml} \%)$ & Sterilizing Rate \\
\hline PE ETT & - & 0 & 0 \\
\hline TEOS/KH570/MTES & $15: 6: 1$ & 0 & 0 \\
\hline \multirow[t]{5}{*}{ TEOS/KH570/MTES/Ag-SiO ${ }_{2}$} & $15: 6: 1: 0.2$ & 0.9 & $71.3 \%$ \\
\hline & $15: 6: 1: 0.4$ & 1.8 & $71 \%$ \\
\hline & $15: 6: 1: 0.6$ & 2.6 & $93.5 \%$ \\
\hline & $15: 6: 1: 0.8$ & 2.5 & $93.7 \%$ \\
\hline & $15: 6: 1: 1.0$ & 4.3 & $93.3 \%$ \\
\hline
\end{tabular}

Table 3: The antimicrobial property of the silicone-modified antimicrobial PE ETT with or without $\mathrm{Ag}-\mathrm{SiO}_{2}$.

on PE ETT surface with different $\mathrm{Ag}-\mathrm{SiO}_{2}$ content can be researched and tested by the method described as GB/T 21866-2008, and the results are showed in the Table 3. The PE ET T and PE ETT coated with TEOS/KH570/MTES without $\mathrm{Ag}-\mathrm{SiO}_{2}$ have no antimicrobial effect. The sterilizing rate increased non-linear with the increasing of $\mathrm{Ag}-\mathrm{SiO}_{2}$ content. When the ratio of $\mathrm{Ag}-\mathrm{SiO}_{2}$ is $2.6 \%$, the sterilizing rate of antimicrobial PE ETT were up to $93.5 \%$, but there is not obvious change for the sterilizing rate by increasing $\mathrm{Ag}-\mathrm{SiO}_{2}$ content. The results indicated that the content of silver is an important factor which influences the antimicrobial properties of the obtained films and it is desirable to contain at least $2.6 \%$ by volume or more.

\section{Analysis for the stabilities of $\mathbf{A g}^{+}$ion}

In order to research the stability of silver, the antimicrobial film was dipped in hot water for $24 \mathrm{~h}$, then the extraction of $\mathrm{Ag}^{+}$ion was measured by ICP-MS, and the results are showed in the Table 4 . The $\mathrm{Ag}^{+}$ ion concentration of the deionized water and the antimicrobial solution

\begin{tabular}{|c|c|c|}
\hline Treating Condition & Samples & $\mathbf{A g}(\boldsymbol{\mu g} / \mathbf{L})$ \\
\hline Deionized water & Blank & 0.002 \\
\hline The film dip in $40^{\circ} \mathrm{C}$ hot-water for $24 \mathrm{~h}$ & A & 0.005 \\
\hline The film dip in $80^{\circ} \mathrm{C}$ hot-water for $24 \mathrm{~h}$ & B & 0.009 \\
\hline The solution diluted 1000 times with deionized water & C & 0.025 \\
\hline
\end{tabular}

Table 4: The extraction of $\mathrm{Ag}^{+}$ion of the silicone-modified antimicrobial PE ETT.

\begin{tabular}{|c|c|c|c|c|c|c|c|}
\hline \multirow{2}{*}{\multicolumn{2}{|c|}{ Sample }} & \multicolumn{3}{|c|}{ Blank ETT } & \multicolumn{3}{|c|}{$\begin{array}{l}\text { silicone-modified antimicrobial PE } \\
\text { ETT with ratio of } 2.6 \% \mathrm{Ag}-\mathrm{SiO}_{2}\end{array}$} \\
\hline & & B1 & B2 & B3 & C1 & $\mathrm{C} 2$ & $\mathrm{C} 3$ \\
\hline \multicolumn{2}{|c|}{$m_{\text {Weight }} / \mathrm{Kg}$} & 2.3 & 2.3 & 2.2 & 2. 2 & 2.2 & 2.2 \\
\hline \multirow[t]{3}{*}{$T_{\text {before }} /{ }^{\circ} \mathrm{C}$} & $\mathrm{Oh}$ & 38.69 & 38.62 & 38.8 & 38.69 & 38.94 & 38.75 \\
\hline & $0.5 \mathrm{~h}$ & 38.63 & 38.5 & 38.86 & 38.69 & 38.87 & 38.69 \\
\hline & $\bar{T}$ & 38.66 & 38.56 & 38.83 & 38.69 & 38.9 & 38.72 \\
\hline \multirow{6}{*}{$T_{\text {after }} /{ }^{\circ} \mathrm{C}$} & $0.5 \mathrm{~h}$ & 38.57 & 38.56 & 38.81 & 38.37 & 38.62 & 38.44 \\
\hline & $1.0 \mathrm{~h}$ & 38.75 & 38.56 & 39.25 & 38.37 & 38.69 & 38.56 \\
\hline & $1.5 \mathrm{~h}$ & 38.75 & 38.69 & 39.31 & 38.25 & 38.69 & 38.63 \\
\hline & $2.0 \mathrm{~h}$ & 38.75 & 38.62 & 39.31 & 38.31 & 38.69 & 38.69 \\
\hline & $2.5 \mathrm{~h}$ & 38.75 & 38.56 & 39.25 & 38.25 & 38.69 & 38.63 \\
\hline & $3.0 \mathrm{~h}$ & 38.69 & 38.56 & 39.25 & 38.37 & 38.81 & 38.75 \\
\hline \multicolumn{2}{|c|}{$\begin{array}{c}\Delta T /{ }^{\circ} \mathrm{C} \\
\Delta T=T_{\text {afte }}-\bar{T}, T_{\text {after }}>\bar{T}\end{array}$} & 0.09 & 0.13 & 0.48 & 0 & 0 & 0.03 \\
\hline \multicolumn{2}{|c|}{$\Sigma \Delta T /{ }^{\circ} \mathrm{C}$} & \multicolumn{3}{|c|}{0.7} & \multicolumn{3}{|c|}{0.03} \\
\hline
\end{tabular}

Table 5: The results of pyrogen test of blank ETT and silicone-modified antimicrobial PE ETT with ratio of $2.6 \% \mathrm{Ag}^{-\mathrm{SiO}_{2}}$.

\begin{tabular}{|c|c|c|c|c|}
\hline Sample & H1 & H2 & H3 & H4 \\
\hline$A$ & 0.0157 & 0.0170 & 0.0110 & 0.8097 \\
\hline$H R / \%$ & 0.5885 & 0.7512 & - & - \\
\hline
\end{tabular}

Table 6: The hemolytic ratio of blank ETT and silicone-modified antimicrobial PE ETT with ratio of $2.6 \% \mathrm{Ag}-\mathrm{SiO}_{2}$.

of TEOS/KH570/MTES/Ag-SiO are $0.002 \mu \mathrm{g} / \mathrm{L}$ and $0.025 \times 1000 \mu \mathrm{g} / \mathrm{L}$, respectively. We can see that silver in the antimicrobial solution is about 10000 times more than deionized water. But, in the sample A and sample B, the $\mathrm{Ag}^{+}$ion concentration are $0.005 \mu \mathrm{g} / \mathrm{L}$ and $0.009 \mu \mathrm{g} / \mathrm{L}$, respectively, only a little higher than deionized water. That affirms that the $\mathrm{Ag}-\mathrm{SiO}_{2}$ has been homogeneously dispersed in the antimicrobial film and firmly chemically bonded with the silicon compound solution. It means that the firm chemical bond is established between Ag antibacterial agent and composite silicone sol and the cohesiveness between antibacteraial coating and ETT base material surface is strong. It can keep antibacterial property for a long time to extend ETT's use time to certain extent and decrease drawing times thus to reduce inflammation occurance probability.

\section{Biosecurity}

Pyrogen test, hemolysis test and oral mucous irritation test are conducted for the blank ETT and the silicone-modified antimicrobial PE ETT with ratio of $2.6 \% \mathrm{Ag}-\mathrm{SiO}_{2}$ in order to investigate security of the silicone-modified antimicrobial PE ETT with ratio of $2.6 \% \mathrm{Ag}$ $\mathrm{SiO}_{2}$. The results of pyrogen test are shown as data in Table 5. The total rose temperature is $0.7^{\circ} \mathrm{C}$ for blank ETT and $0.03^{\circ} \mathrm{C}$ for the siliconemodified antimicrobial PE ETT with ratio of $2.6 \% \mathrm{Ag}-\mathrm{SiO}_{2}$, which are fit for pyrogen inspection range regulated in the standard of Chinese Pharmacopoeia (Version 2010). It is indicated no pyrogenic effect caused by materials for the silicone-modified antimicrobial PE ETT with ratio of $2.6 \% \mathrm{Ag}-\mathrm{SiO}_{2}$ and better cohesion between antibacterial coatings and ETT which is not easy for dipping and precipitation. The 


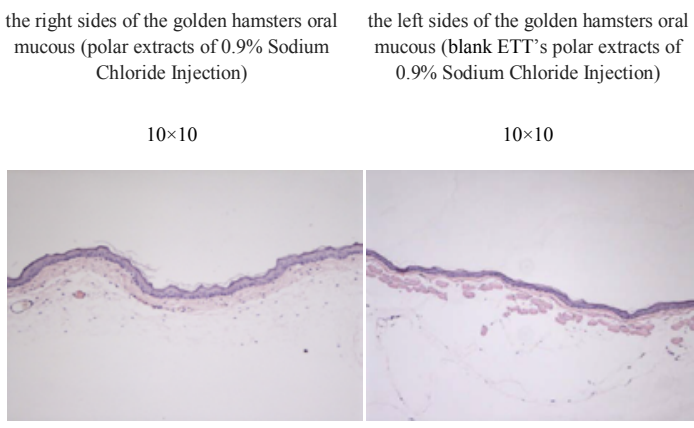

$10 \times 40$

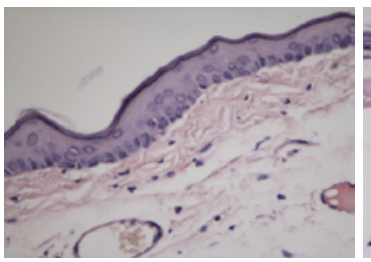

the right sides of the golden hamsters oral mucous (non polar extracts of cottonseed oil)

$10 \times 10$

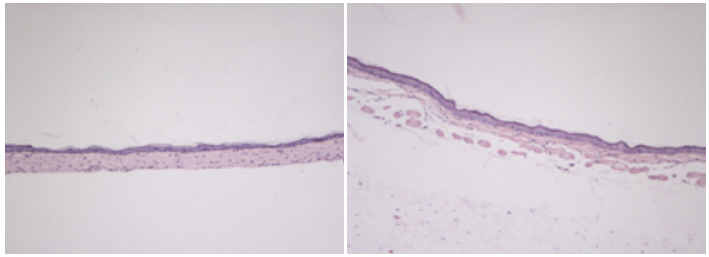

$10 \times 40$

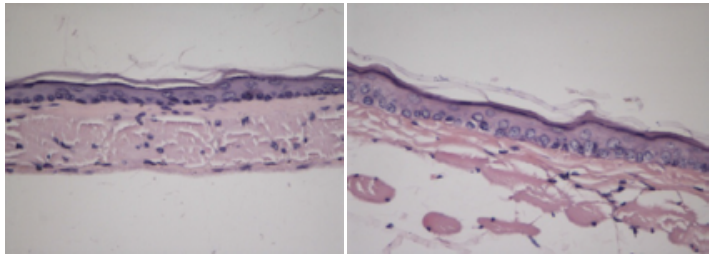

the left sides of the golden hamsters oral mucous (silicone-modified antimicrobial PE ETT's polar extracts of $0.9 \%$ Sodium Chloride Injection)

$10 \times 10$

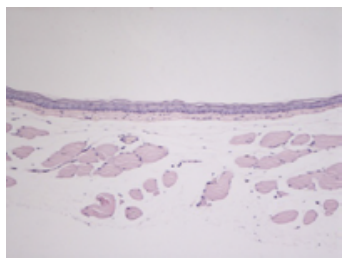

$10 \times 40$

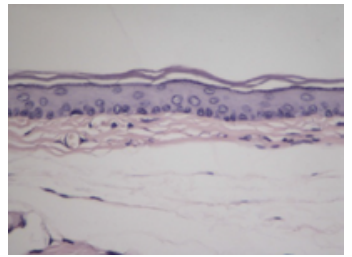

the left sides of the golden hamsters oral mucous (silicone-modified antimicrobial PE ETT'snon polar extracts of cottonseed oil)

$10 \times 10$

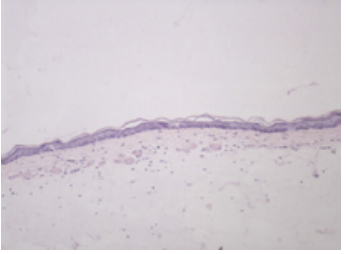

$10 \times 40$

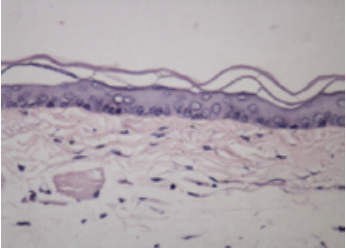

Figure 6: The golden hamsters oral mucous irritation test of the blank ETT and the silicone-modified antimicrobial PE ETT with ratio of 2.6\% Ag-SiO ${ }_{2}$

dipping liquid injecting into rabbit blood is guaranteed not to cause temperature rise reaction and keeps rabbit's temperature.

The results of hemolysis test are shown as data in Table 6 . Absorbance $\mathrm{A}$ in the table is the average absorbance of three same samples. The average absorbance of negative control liquid and positive control liquid is 0.0110 and 0.8097 respectively. The test complies with requirements and the results are valid. The hemolysis ratio of the blank ETT (H1) and the silicone-modified antimicrobial PE ETT with ratio of $2.6 \% \mathrm{Ag}-\mathrm{SiO}_{2}(\mathrm{H} 2)$ is $0.5885 \%$ and $0.7512 \%$ respectively. The hemolysis ratio should be less than $5 \%$ according to the standard of Biological Evaluation of Medical Devices: GB/T16886.4-200 Temolysis Test Inspection. It is found that hemolysis test of the silicone-modified antimicrobial PE ETT with ratio of $2.6 \% \mathrm{Ag}-\mathrm{SiO}_{2}$ is qualified and it is testified that antibacterial ETT is safe to red cell of human body.

According to GB/T16886.10-2005 standard, the results of the golden hamster oral mucous irritation test of the blank ETT and the siliconemodified antimicrobial PE ETT with ratio of $2.6 \% \mathrm{Ag}-\mathrm{SiO}_{2}$ are shown in Figure 6. The extracts of the blank ETT and the silicone-modified antimicrobial PE ETT with ratio of $2.6 \% \mathrm{Ag}-\mathrm{SiO}_{2}$ showed no irritation reactions to golden hamsters oral mucous. Both the right and left sides of oral mucosals were epithelial integrity, they had no proliferation of epithelial cells, flattened, degeneration or necrosis, submucosal had no congestion, edema, inflammatory infiltration and necrosis and or other pathological changes. The two groups' oral mucosal tissue reactions of acute exposure were scored 0 , showing no irritation.

Above all, the silicone-modified antimicrobial PE ETT with ratio of $2.6 \% \mathrm{Ag}-\mathrm{SiO}_{2}$ is fit for biosecurity use requirement for biological materials.

\section{Discussion}

In this paper, the silicon compound of $\mathrm{SiO}_{2} / \mathrm{KH} 570$ and $\mathrm{SiO}_{2} /$ 
Citation: Xuhong J, Bin LV, Xinmin W, Qianhong S (2014) Preparation of the Silicone-Modified Antimicrobial Polyethylene Endotracheal Tube (PE ETT). J Med Microb Diagn 3: 163. doi:10.4172/2161-0703.1000163

KH570/MTES prepared through the sol-gel process with TEOS as inorganic silicon source, KH570 and MTES as the organicsilicon source, were used to prepare series silicone-modified antimicrobial films on conventional PE ETT. By researching and analysising the characterization of antimicrobial PE ETT, we determine the proportion of the TEOS/KH570/MTES/Ag-SiO 2 (15:6:1:0.6 1.0) films with ratio at least $2.6 \%$ to prepare silicone-modified antimicrobial $\mathrm{PE}$ ETT. The silicone-modified antimicrobial PE ETT coated by TEOS/ KH570/MTES/Ag-SiO (15:6:1:0.6 1.0) films with ratio at least $2.6 \%$ has the high transmittance of above $87 \%$, high hardness of $5 \mathrm{H}$, and strong adhesion, exhibits excellent antimicrobial property with the sterilization rate up to $93.5 \%$. What's more, it is proven in the pyrogen test, hemolysis test and oral mucous irritation test that the siliconemodified antimicrobial PE ETT has excellent biocompatibility and biosecurity of requirement for biological materials and equipped with excellent physical and biological properties. It is hoped to be used in the field of coated materials for medical materials or medical equipment to improve infection situation in the hospital.

\section{References}

1. Pinciroli R, Mietto C, Berra $L$ (2013) Respiratory therapy device modifications to prevent ventilator-associated pneumonia. Curr Opin Infect Dis 26: 175-183.

2. O'Grady NP, Murray PR, Ames N (2012) Preventing ventilator-associated pneumonia: does the evidence support the practice? JAMA 307: 2534-2539.

3. Geilich BM, Webster TJ (2013) Reduced adhesion of Staphylococcus aureus to ZnO/PVC nanocomposites. Int J Nanomedicine 8: 1177-1184.
4. Lin H, Xu Z, Wang X, Long J, Su W, et al. (2008) Photocatalytic and antibacteria properties of medical-grade PVC material coated with TiO2 film. J Biomed Mater Res B Appl Biomater 87: 425-431.

5. Yao Y, Ohko Y, Sekiguchi Y, Fujishima A, Kubota $Y$ (2008) Self-sterilization using silicone catheters coated with $\mathrm{Ag}$ and $\mathrm{TiO} 2$ nanocomposite thin film. $J$ Biomed Mater Res B Appl Biomater 85: 453-460.

6. Hench LL, Polak JM (2002) Third-generation biomedical materials. Science 295: 1014-1017.

7. Politano AD, Campbell KT, Rosenberger LH, Sawyer RG (2013) Use of silver in the prevention and treatment of infections: silver review. Surg Infect (Larchmt) 14: 8-20.

8. Xu YF (2012) Anti-bacterial and adhesion ability of antibacterial biomaterials Chinses Journal of Tissue Engineering Research 16: 9671-9678.

9. Hui Yang, Yan Liu, Qianhong Shen. (2012) Mesoporous silica microcapsulesupported Ag nanoparticles fabricated via nano-assembly and its antibacterial properties. Journal of Materials Chemistry 22: 24132-24138.

10. Chan-Hee Park, Leonard D Tijing, Cheol Sang Kim, Michael Tom G Ruelo (2012) One-step fabrication of antibacterial (silver nanoparticles/poly(ethylene oxide))-Polyurethane bicomponent hybrid nanofibrous mat by dual-spinneret electrospinning. Materials Chemistry and Physics 134: 557-561.

11. An J, Ji Z, Wang D, Luo Q, Li X (2014) Preparation and characterization of uniform-sized chitosan/silver microspheres with antibacterial activities. Mater Sci Eng C Mater Biol Appl 36: 33-41.

12. Wang F, Luo ZK, Qing SG, Qiu Q, Li RF. (2009) Sol-gel derived titania hybrid thin films with refractive index. Journal of Alloys and Compounds 486: 521-526.

13. Zhang HB, Wang JY, Li LK, Song Y, Zhao MS et al. (2008) Synthesis of liquid polysilisiquioxane resins and properties of cured films. Thin Solid Films 517 857-862. 